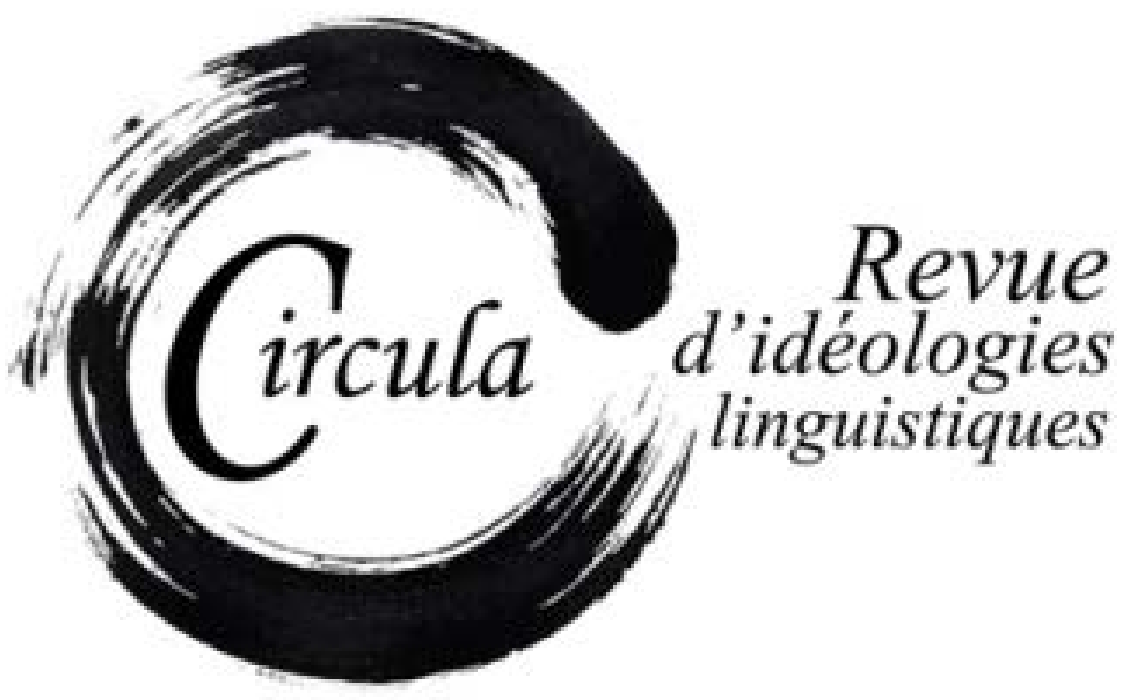

TITRE: LA GRAMATICOGRAFÍA RUSA SOBRE LA FONÉTICA ESPAÑOLA: ¿UN CANON IDEOLÓGICO DE BASE PERCEPTIVA?

Auteur(s): Olga IVANOVA, Universidad de SALAmanca

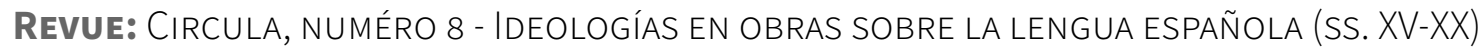

PAgES: $52-69$

ISSN: 2369-6761

Directeurs: : Francisco Escudero Paniagua, Carlos VillanueVa García, Carmen Quijada Van DEN BERGHE, José Jesús Gómez AsEnCIO

URI: HTTP://HDL.HANDLE.NET/11143/15551

DOI: HTTPS://DOI.ORG/10.17118/11143/15551 


\title{
La gramaticografía rusa sobre la fonética española: ¿Un canon ideológico de base perceptiva?
}

\author{
Olga Ivanova, Universidad de Salamanca \\ olga.ivanova@usal.es
}

\begin{abstract}
Resumen: Las primeras ideas sobre la fonética española y, particularmente, sobre la forma de sonar del español, surgen en el pensamiento ruso decimonónico dentro del ámbito de la musicología y la crítica literaria. Debido a un mayor interés por el alemán y el francés, dos lenguas europeas de mayor prestigio en el Imperio Ruso, la lingüística rusa deja de lado el posible interés por el español que, por el contrario, empieza a despertar la curiosidad de compositores como Glinka o críticos literarios como Botkin. Surge, así, una primera ideología rusa sobre cómo suena el español; ideología que, como intentará demostrar este trabajo, repercutirá en las posteriores conceptualizaciones gramaticales de la fonética española desde Rusia en el siglo XX. En estas, se podrá rastrear hasta la actualidad la directa influencia de las percepciones surgidas y fomentadas en torno a los elementos segmentales y suprasegmentales del español en el siglo XIX en el contexto de la creación musical.
\end{abstract}

Palabras-clave: fonética española; Rusia; musicología; percepción; estudios comparados

Abtract: The first ideas about Spanish phonetics, particularly, about Spanish sound form, emerged in Russian thoughts of the $19^{\text {th }}$ century in the context of musicology and literary criticism. Russian linguistics of the time had a greater interest in German and French, the two most prestigious European languages of the Russian Empire, than in Spanish, which started to arouse the curiosity of composers like Glinka and literary critics like Botkin. In such a way, there emerged the first Russian ideology about how the Spanish sounds, which, as this work will try to demonstrate, will make a remarkable impact on further grammar conceptualizations of Spanish phonetics in Russia during the $20^{\text {th }}$ century. These conceptualizations reflect until today the direct influence of first perceptions, which were created during the $19^{\text {th }}$ century about segmental and suprasegmental elements of Spanish in the context of musical composition.

Keywords: Spanish phonetics; Russia; musicology; perception; comparative studies 


\section{Introducción}

El tratamiento ideológico de una lengua suele darse desde el interior de la misma. En otras palabras, es más común encontrar en la historia del pensamiento lingüístico trabajos ideológicos sobre el inglés en el ámbito anglosajón; sobre el alemán, en el ámbito germano, y sobre el español, lógicamente, en el ámbito hispano. Menos común, por no decir prácticamente ausente, es la práctica del tratado ideológico sobre una lengua desde un ámbito sociocultural que le es completamente ajeno. Este hecho es esperable si se tiene en cuenta la distancia que separa no solo la lengua objeto del pensamiento ideológico de su entorno funcional, sino también a los propios ideólogos de su objeto de estudio en todos sus aspectos.

No obstante, en esta práctica del pensamiento ideológico - aquel que vierte sobre el material lingüístico marcas ideológicas que representan la concepción del mundo, los ideales, las aspiraciones o los principios morales compartidos por un grupo (Calero Vaquera, 2010) - se da un caso interesante de la reflexión sobre una lengua no propia, que en este trabajo se definirá bajo el adjetivo englobador "rusa". En esta, como se verá más adelante, se enmarca la actividad filológica de varios siglos, particularmente, de los siglos XIX y XX, que abarcan varias épocas políticas: la del final del Imperio Ruso, la de la Unión Soviética y la de la Rusia actual. Estas épocas, divididas políticamente, están fuertemente unidas (o, mejor dicho, ajenas a una posible separación) por un eje lingüístico específico en lo que concierne la formulación y el fomento del pensamiento ideológico sobre diferentes lenguas europeas, en particular, sobre el español.

Al igual que en otros países europeos, las primeras escuelas lingüísticas y, con ellas, las primeras obras ideológicas surgieron en Rusia a partir del auge de la teoría comparativa. Aquellas primeras obras de la lingüística rusa de los siglos XIX y XX se centraron, fundamentalmente, en el estudio de las numerosas lenguas autóctonas del Imperio Ruso y, posteriormente, la URSS, y en dos de las lenguas europeas de mayor prestigio: el francés y el alemán. La ascendencia de la propia familia real rusa a las casas reales germanas tuvo mucho que ver en el gran valor que se le atribuía al alemán. El francés, por su parte, encontró lugar entre los principales objetos de estudio lingüístico por ser la lengua de moda debido a su legado en la literatura, la ópera y la vida social. Poco espacio le quedaba, inicialmente, al español: una lengua poco conocida, sin apenas nativos residentes en el territorio del Imperio, y con poco calado histórico en las obras gramaticales y lexicográficas.

El español, a pesar de suscitar mucho interés científico y personal, apenas encontró hueco en las obras gramaticales o lexicográficas de la lingüística imperial decimonónica. De su descripción funcional e ideológica, sin embargo, se ocupó la élite artística del Imperio Ruso del siglo XIX: escritores, músicos, viajeros; todos, apasionados visitantes de España y, sin querer, los primeros "hispanistas" rusos. Como se intentará demostrar en este trabajo, el hecho de que las primeras observaciones metalingüísticas sobre el español provinieran de personas ajenas a la lingüística y cercanas al mundo del arte, determinará a lo largo de toda la historia hispanística rusa una postura ideológica particular: 
una visión perceptivo-afectiva, que se origina en el contexto de las primeras "obras" sobre el español en Rusia. En este sentido el eje fundamental de este trabajo es la consideración de que la visión que se creó del español dentro del mundo del arte decimonónico ruso, siempre en comparación con otras lenguas del momento, como el francés o el alemán, va a condicionar que toda la posterior lingüística hispánica rusa refleje la particular visión artística en obras puramente filológicas.

El objetivo del presente trabajo es, por tanto, demostrar a partir del análisis de un corpus de obras de diferente tipología, que la perspectiva gramatical actual en la hispanística rusa debe su enfoque en la descripción del español a las visiones perceptivas de los intelectuales vinculados al mundo de la música y el arte del siglo XIX. Para ello, utilizaremos, en primer lugar, como fuentes directas una serie de textos que nada tienen que ver con la labor lingüística, pero contienen en sí unas claras referencias a las primeras "ideas" sobre cómo es la lengua española. Consideraremos estos textos, siguiendo a Gómez Asencio, Montoro del Arco y Swiggers (2014: 269), como textos de entorno que, como intentaremos demostrar a lo largo de todo el trabajo, sirven como punto de partida para el ideario lingüístico sobre la lengua española y, particularmente, sobre su fonética. En segundo lugar, utilizaremos como fuentes otros dinamotipos textuales (de síntesis y de reacción sobre todo) elaborados desde finales del siglo XIX hasta principios del siglo XXI, con el objetivo de trazar el reflejo de las primeras ideas sobre el español en la teoría gramatical actual. En este estudio, defenderemos que las primeras fuentes que cimientan la ideología sobre la fonética española son documentos privados -notas, correspondencias, cartas, apuntes- que los humanistas decimonónicos utilizaban para ofrecer las primeras reflexiones sobre "el sonido del español" y su funcionalidad. En ello, reflexionaremos, tal y como considera importante y necesario Swiggers (2004: 115), sobre el surgimiento de las primeras ideas sobre el español en el ámbito ruso y su condicionamiento sociocultural, y, a continuación, demostraremos cómo estas ideas aún quedan reflejadas no solo en la norma académica de la hispanística rusa sino también en la percepción popular.

\section{La lengua española en la lingüística rusa: ¿ hay lugar para un estudio historiográfico?}

Si consideramos que la historiografía es la "ciencia crítica de la historia" del pensamiento lingüístico (Laborda, 2002: 180), es lógico plantearse si, en nuestro caso, la historiografía lingüística del español puede existir fuera del dominio sociocultural y político de esta lengua. En otras palabras, si existe un fundamento real para poder hacer una retrospección crítica en el tratamiento metalingüístico de la lengua española en un país como, en el siglo XIX, fue el Imperio Ruso. La primera respuesta resulta tan controvertida como el propio planteamiento: la lingüística rusa ha tenido, desde sus albores, el propio ruso, las lenguas emparentadas con él y otros numerosísimos idiomas del Imperio ${ }^{1}$ como su principal objeto de estudio, relegando otros códigos idiomáticos a un lugar secundario. Sin embargo, la apertura de la dinastía Romanov a Europa y a su cultura dio lugar a un gran interés por las

1. Según los datos de Comrie (1981), en la Unión Soviética, heredera del Imperio Ruso, se hablaban unas 130 lenguas. 
lenguas europeas. Entre ellas, el español nunca tuvo un lugar central y, de hecho, estuvo ausente en la mayoría de las obras lingüísticas de los siglos XVIII y XIX. Precisamente ello, como se intentará demostrar a continuación, dio lugar a que las raíces de la hispanística rusa brotaran en un contexto que nada tenía que ver con la lingüística, y ello ha estado determinando hasta nuestros días la perspectiva ideológica sobre el español en la sociedad rusohablante. Existe, por tanto, una posibilidad para la historiografía del español en la lingüística rusa, cuyo recorrido solo se puede entender en el contexto del poco calado que tuvo frente a idiomas tan influyentes como el francés o el alemán.

Al igual que en muchos países europeos, las primeras teorías lingüísticas (strictu sensu) rusas datan de los años 30 y 60 del siglo XIX, cuando se desarrolla la noción y la aplicabilidad del método histórico-comparativo (Berezin, 1984: 58). El uso de aquel método se focalizó, entonces y a largo plazo, en el estudio de las relaciones de parentesco entre las tres lenguas eslavas orientales -el ruso, el ucraniano y el bielorruso- que, entre otras cosas, respondía a las necesidades de una ideología sociopolítica muy marcada de aquel momento: demostrar la dependencia dialectal del ucraniano y del bielorruso de la lengua rusa, con el fin de conseguir una definitiva erradicación funcional de los mismos (Ivanova, 2011: 185-187).

En cuanto a diferentes lenguas europeas, la lingüística decimonónica rusa se centró, fundamentalmente, en el estudio de las lenguas de prestigio del momento: el alemán y el francés, sin que quedara mucho espacio para el estudio de la lengua española. Tampoco las obras lingüísticas precursoras del propio surgimiento de la lingüística como tal habían elegido el español como su objeto de estudio. El desmesurado interés por el alemán, pero sobre todo por el francés, estaba fuertemente vinculado a la gran presencia de intelectuales alemanes y al papel que la lengua francesa desempeñaba en el ámbito científico a nivel europeo (Klubkova, 2016: 182).

La corroboración de este hecho se encuentra en las obras lingüísticas más destacadas del siglo XVIII, periodo en el que el Imperio Ruso vivió una importante europeización social y política y se interesó, dentro de aquel proceso, por las lenguas europeas. De estas, fueron ante todo el alemán y el francés, con gran perjuicio de otras lenguas modernas del momento, los principales objetos del estudio lingüístico comparativo en el Imperio Ruso. En el claro intento de la normalización y la estandarización del propio ruso (Alpatov, 2005: 52), surgieron numerosos trabajos que comparaban su fonética, léxico y gramática con los mismos niveles de los clásicos latín y griego y, en la vertiente de las lenguas vivas, del alemán y el francés.

Así, pues, en los trabajos de Mijail Lomonosov, considerado el precursor de la lingüística rusa moderna e interesado sobre todo por los orígenes y la dialectalización de las lenguas eslavas, encontramos una clara focalización en el alemán. En su Sobre el parecido y los cambios en diferentes lenguas (О сходстве и переменах языков) (1755)², del que no se conserva copia (Lebedev, 2010), pero que nos ha llegado parcialmente en apuntes y correspondencias, comparó las formas de los primeros

2. De aquí en adelante las traducciones de los títulos de las obras citadas al español son nuestras. Lo mismo aplica a las citas procedentes de dichas fuentes. 
diez numerales en ruso con las formas en griego, latín y alemán. La selección del alemán no fue azarosa, y no solo porque el propio Lomonosov, como sus coetáneos, había estudiado esta lengua en la universidad. Su criterio siguió, de forma esperable, las ideas lingüísticas más destacadas del momento, reflejadas en los germanos Wilhelm von Leibniz, Christian von Wolff o Johann Christoph Gottsched (Filippov, 2013: 253 y ss.).

Con más intensidad, la ausencia del español queda patente en los trabajos lexicográficos multilingües de la segunda mitad del siglo XVIII. Así, no aparece mención alguna del español en el cuestionario lingüístico de Ludwig Bacmeister, Idea et desideria de colligendis linguarum speciminibus (1773), publicado en ruso, latín, francés y alemán, y con ejemplos en árabe, sueco y finés. Aquel cuestionario, considerado precursor de la lingüística de campo, dejó patente la idea sobre el gran valor del francés y el alemán sobre otras lenguas europeas, que el autor prescindió de enumerar. El valor del francés y el alemán es tal que el autor literalmente sugiere utilizar, y utiliza personalmente ambas para representar las reglas de pronunciación de otras lenguas, para "especialmente mostrar cómo se pronuncian” (Bacmeister, 1773: s. p.). Así habla de la supremacía del francés, y luego del alemán, sobre otras lenguas europeas: "Para mostrar cómo se pronuncia [...], tome [como lengua de traducción] una lengua que conoce bien, preferiblemente el francés, luego el alemán, y solo luego cualquier otra lengua europea bien conocida" (Bacmeister, 1773: s. p.).

El resultado directo del trabajo de Bacmeister, el diccionario comparado de las lenguas de Simeón Pallas, titulado Linguarum totius orbis vocabularia comparative augustissimae cura collecta (17871789), encargado y supervisado personalmente por la emperatriz Catalina II, tampoco tuvo un lugar para la lengua española. Este diccionario, considerado equiparable en el reflejo de la diversidad lingüística del mundo a Mithridates, oder allgemeine Sprachenkunde, de Johann Adelung y Johann Vater; al Catálogo de las lenguas de las naciones conocidas, de Lorenzo Hervás, o a Asia Poliglotta, de Heinrich Klaproth (Klubkova, 2016: 182), pretendía ofrecer la traducción de toda palabra rusa a todas las posibles lenguas extranjeras que, en su totalidad, alcanzaban 200 (Kaminskaia, 2015: 71-72). Entre estas, el español aparece como una lengua destino de traducción -el orden correlativo del español es el 25 sobre 200, por detrás del vasco (15), córnico (19) o napolitano (24)-, pero nunca como una lengua funcional que sirva al autor para tareas lingüísticas. Entre estas, destaca la explicación de cómo se pronuncian los equivalentes de las palabras rusas objeto del diccionario en las 200 lenguas elegidas, tarea para la que Pallas adopta una postura muy acorde a las tradiciones lingüísticas del siglo XVIII: transliterarlos en alfabeto cirílico y explicar, cuando parecía necesario, las particularidades de la pronunciación si una grafía rusa no representaba fehacientemente la pronunciación nativa. En esta tarea, recurre a comparaciones con fonemas de otras lenguas, como el griego, el latín, el alemán, el francés o el italiano, pero nunca el español, hecho que refleja una postura ideológica reveladora: el español no era lengua conocida que pudiera servir de referencia para saber articular bien una palabra extranjera. 
La centralización en el alemán y el francés como objeto de estudio lingüístico predominó durante todo el s. XVIII y la primera mitad del s. XIX. El francés, de hecho, se postuló como una lengua modelo, puesto que los franceses "después de limpiary decorar su lengua por medio del trabajo de escritores con mucho arte" consiguieron que el uso del francés "se extendiera por toda Europa y más allá" (Lomonosov, citado en Zhivov, 1996: 273). La escasa curiosidad lingüística por el español convive, paradójicamente, con el excesivo interés por la literatura española que, inesperadamente, se traduce al ruso desde sus versiones en francés o alemán. Tal fue el caso de la primera traducción de El escondido y la tapada, de Pedro Calderón de la Barca, hecha a finales del siglo XVIII, o de El médico de su honra, del mismo autor, traducida desde el alemán por el dramaturgo ruso Karatyguin hacia el 1831 (Kogan, 1989). Aquellas traducciones dobles fueron ampliamente criticadas por "estropear la obra [... .] haciendo que muchos pasajes fuesen poco o incluso nada comprensibles" (Kogan, 1989).

En este contexto de clara centralización lingüística en las lenguas imperiales, clásicas y el par alemán-francés, surgió en el pleno siglo XIX una serie de ideas sobre el valor y los rasgos de la lengua española. La apertura de muchos creadores artísticos y literarios a viajes por Europa llevó a algunos compositores, músicos y humanistas rusos a la España de la segunda mitad del siglo XIX, donde estudiaron el español en pleno contexto de inmersión. A la vuelta a Rusia, aquellos intelectuales ajenos a la lingüística reflejaron sus ideas de calado casi metalingüístico sobre el gran desconocido que era el español. Ante todo, se centraron en su forma de sonar, el aspecto de su mayor interés teniendo en cuenta que la ideología se estaba creando en el ámbito de la musicología, y no de la filología propiamente dicha. Así surgieron los primeros "trabajos" sobre aspectos fonéticos y fonológicos del español que, como se verá más adelante, encontraron reflejo en las concepciones académicas de toda la posterior hispanística rusa.

\section{Los inicios del paradigma ideológico sobre la fonética española}

Sin excluir las posibilidades de tratar los diferentes niveles lingüísticos del español en su totalidad, parece que el nivel que más destaca por su influencia en toda la posterior tradición gramaticográfica rusa sobre el español es la fonética. En este trabajo hacemos por tanto una delimitación tópica, utilizando la terminología de Gómez Asencio, Montoro del Arco y Swiggers (2014: 267), centrándonos de forma exclusiva en la historiografía de la fonética española en el canon ruso.

En el siglo XIX, muchos humanistas (compositores, músicos, escritores) rusos visitaron España, para entonces, la gran aliada del Imperio Ruso después de las guerras napoleónicas.

Entre los primeros en dejar apuntes sobre la fonética española se encuentra Mijail Glinka, un gran compositor del siglo XIX que, entre otras cosas, destacó por crear la ópera rusa nacional. Su viaje a España en 1845 fue impulsado por la búsqueda de nuevas inspiraciones musicales en la cultura y en el folclore español, que compaginó con el estudio de la lengua española. La experiencia de aquel viaje de larga duración, que no volvió a repetirse, fue reflejada en sus Cartas (Письма), pero 
sobre todo en sus Notas (Записки), que el compositor abrió con una expresión reveladora: “Entré en España el 20 de mayo, el día de mi cumpleaños, y quedé encantado”3.

En estos documentos, encontramos las primeras apreciaciones que Glinka estableció sobre la lengua española. Pasan, a nuestro parecer, por tres fases de conceptualización de lo español, dando lugar a una idea muy clara sobre su fonética y prosodia. La primera fase da cuenta del contacto de Glinka con la lengua española, y nos sorprende por su asombro inesperado ante la aparente dificultad de aprenderla, reflejo del gran desconocimiento sobre ella en la sociedad de donde provenía el compositor. Encontramos, sobre todo en sus Cartas, las siguientes observaciones:

1. "Gracias a que vivo con una familia, estoy viendo su forma de vivir, sus costumbres y estoy aprendiendo la lengua [española], que no es para nada fácil" (Glinka 2012: 906)4 (la cursiva es nuestra);

2. "Apenas salgo antes de comer porque hace un calor insoportable; mi mañana se va en escribir cartas y el diario, en el que apunto todo lo que me ocurre día a día, y en aprender la lengua española (que es incomparablemente más difícil que el italiano)" (Glinka 2012: $904)^{6}$;

3. "Ahora estoy empezando a hablar español con tal soltura que incluso los españoles se sorprenden, más aún porque pensaban que un ruso como yo tendría bastantes más dificultades para aprender su lengua" (Glinka: 933)7;

La segunda fase del interés se manifiesta en la focalización de Glinka en los aspectos de la entonación, que, para él, era la única vía de acceder a la esencia no solo de la lengua española, sino también de sus hablantes. Según Asafiev (1978), gran conocedor del compositor, Glinka era consciente de que la entonación debía formar parte esencial del proceso de aprendizaje del español, en tanto que sin comprenderla correctamente era imposible alcanzar a comprender a los españoles, y más en el contexto de la gran italianización decimonónica de la música española que ocultaba el verdadero ser de España. La idea de que la entonación del español podía explicar la música popular hispana fue fundamental para el surgimiento del pensamiento de Glinka sobre la fonética española en la tercera fase, en la que su dominio del español ya le permitía opinar sobre las diferencias entre el

3. "Я вступил в Испанию 20 мая, в самый день моего рождения, и был в совершенном восторге".

4. “Живя в семействе, я знаю домашний быт, изучаю нравы и начинаю порядочно говорить на языке, который совсем не легок".

5. De aquí en adelante los resaltes en cursiva en los ejemplos son nuestros.

6. “До обеда редко выхожу, на солнце нестерпимо жарко, письма, журнал, в коем записываю случающееся ежедневно, и изучение испанского языка (который несравненно труднее италианского) наполняют утро”.

7. “Теперь я начинаю говорить по-испански с такой свободой, что испанцы удивляются тем более, что им казалось, что мне, как русскому по происхождению, изучение их языка, может, будет гораздо более трудно". 
castellano (el español puro, en sus propios términos) y el andaluz comparándolas con las existentes entre el ruso y el ucraniano ${ }^{8}$.

4. "Dado que me dedico mayoritariamente al aprendizaje del español, en el que tengo ya tanta soltura como antes en italiano, visito con mucha frecuencia el teatro dramático que es, por cierto, muy bueno. Las puestas en escena de tragedias y comedias son igualmente impecables. La lengua española suena fuerte, expresiva y bastante agradable al oído" $(\text { Glinka 2012: 938) })^{9}$

De acuerdo con la percepción que creó en torno a la prosodia española, Glinka, en las mismas fuentes, mostró su rechazo del francés a favor del español como lengua de obras musicales:

5. "La lengua francesa es encantadora en los labios de una mujer guapa pero, en mi opinión, es un asco como lengua de la ópera. Ya he rechazado la propuesta de editar varios romances traducidos al francés" (Glinka, 1973-1977:199) ${ }^{10}$.

Tishko y Kukol (2011: 251) interpretan esta afirmación como una intención de Glinka de editar dichos romances en español, algo que, sin embargo, no sucedió.

6. El drama que interpretaron en español no sonó nada mal” (Glinka, 2012: 895-896)"11;

7. "Aquí todo [también la lengua] respira alegría"12 (Glinka, 2012: 929);

8. "Mi música se pierde en francés, y ahora estoy haciendo gestiones para que mis romances se traduzcan al italiano y al español, para ser editados luego en París" (Glinka, 1973-1977: $180)^{13}$;

9. "[Tengo] la intención de escribir algo muy serio en españoly, para ello, 10 meses en España no son suficientes" (Glinka, 2012: 911) $)^{14}$.

En opinión de Glinka, que pasó una larga temporada en Andalucía, el elemento árabe del español tuvo un papel esencial en su forma de sonar:

8. “Каждый поет по-своему, сверх того, здесь, в Андалузии, говорят наречием особенным, которое отличается от кастильского (чистого испанского) столько же”, по его мнению, сколько “малороссийское от русского” (Glinka, 2012: 974).

9. “Так как я теперь более вего занимаюсь изучением испанского языка и говорю столь свободно как прежде по-италиански, более всего посещаю драматический театр, который очень хорош. Играют трагедии и комедии с ровным совершенством. Испанский язык силён, выразителен и довольно приятен для слуха."

10. “Французский язык, восхитительный в устах милой женщины, по-моему - отвратителен в большой опере. Я должен был отказаться от намерения издать несколько романсов в французском переводе.”

11. "Играли драму на испанском языке, и довольно порядочно."

12. “Здесь все дышит весельем."

13. "Моя музыка теряет на французском языке, и теперь я хлопочу о переводе некоторых романсов на итальянский и испанский язык, с тем, чтобы потом издать их в Париже."

14. “Для моего предположения написать что-либо дельно в испанском роде слишком недостаточно 10 месяцев в Испании." 
10. "[El elemento árabe dota al español mediante] los movimientos melódicos, la colocación de las palabras y su carácter decorativo [de una gran originalidad]"15 (Glinka, 1973-1977: 342).

De acuerdo con las observaciones de Glinka, pioneras en lo relativo a la ideología sobre la prosodia española, surgieron enseguida opiniones semejantes en el terreno de la musicología y el humanismo rusos. En línea con Glinka, muchos compositores rusos se unen a la idea de que la expresividad de la suprasegmentación del español -la entonación, el ritmo y la melodía- es inherente al sistema semántico de la lengua y de la cultura española (Narodetskaya, 2010: 75). Ello se manifiesta en que las obras inspiradas en España, en compositores como Glinka y Dargomyzhski, apuestan por una entonación reforzada y particularmente sensual (Shuranov y Mijaliova, 2016: 111) en el reflejo del carácter y la naturaleza de los españoles. Desde el punto de vista perceptivo, en Rimski-Kórsakov encontramos la idea de que lo español es muy virtuoso y dota a las obras de una maestría particular (Crónicas de mi vida musical, 1866), mientras que Dargomyzhski no deja de apuntar que el español suena particularmente precioso.

En las reflexiones del crítico literario Vasili Botkin, uno de los primeros humanistas decimonónicos en realizar un largo viaje por España y editar, a partir del mismo, un libro (Cartas sobre España, 1845), también encontramos la siguiente observación en torno a la lengua española:

11. "Ponga a un hombre español inculto al lado de un francés, un alemán o incluso un inglés, y le sorprenderá su dignidad natural, sus maneras delicadas y su lengua, exacta y pura" (Botkin, 1857: 440) ${ }^{16}$.

En esta misma obra encontramos una reflexión sobre el especial carácter poético y emotivo del español:

12. "[El hombre español] tiene una gran capacidad para improvisar, que solo puede explicarse por la riqueza de la poesía popular, con la que el pueblo aprende a dominar su lengua" (Botkin, 1857: 440-441) ${ }^{17}$.

La idea general de Botkin sobre la forma de hablar de los españoles se mantenía en que su tono a la vez reflejaba dignidad, orgullo e igualdad con los demás (Botkin, 1857: 83), y en que el uso del español dota a cualquier pieza de las emociones e imágenes que no se consiguen representar de otra forma.

15. "Между тем как это большею частью - чисто арабские мелодии [...] Обороты мелодии, расстановка слов и украшения так оригинальны [...]”

16. "Поставьте этого невежественнаго испанского мужика радомъ съ французскимъ, немецкимъ, даже съ англійскимъ мужикомъ, и вы удивитесь его натуральному достоинству, его деликатнымъ манерамъ и его языку, правильному, чистому."

17. “Отсюда его способность къ импровизаціи, которую можно объяснить только именно богатствомъ народной поэзіи, заучая которую народъ непосредственно научается владеть своимъ языкомъ.” 


\section{La fonética española desde las escuelas lingüísticas del siglo XX}

Y bien, ¿cómo podemos estar seguros de que las primeras opiniones sobre la prosodia y la fonética española realmente estuvieron en la base de todo el futuro canon gramaticográfico hispanista ruso? Es una postura ya común en la historiografía del pensamiento ruso aceptar que la imagen de España -el cuadro del mundo español- se formó según el prisma de los intelectuales decimonónicos y caló en toda la posterior percepción de este país, su cultura y su lengua de tal manera que aún hoy en día perdura a pesar de los grandes cambios por los que ha pasado (Astajova, 2011: 60). Al respecto, las ideas de Glinka sobre el español como el reflejo de la pasión y la emotividad a través de su forma de sonar fueron clave en la formación del mito español en el espacio de la cultura rusa (Astajova, 2011: 62).

Si bien muchas gramáticas de la lengua española y estudios fonéticos no necesariamente vinculados a ellas, concebidas y creadas en el espacio ruso a raíz de su popularización desde finales del s. XIX, carecieron de una perspectiva subjetiva que reflejase el susodicho mito español, a lo largo del s. XX encontramos una serie de obras metalingüísticas que han heredado la postura perceptiva sobre la forma de sonar del español cultivada por los intelectuales decimonónicos. Esta se enmarca dentro dos tendencias ideológicas predominantes en la gramaticografía hispanista rusa: por un lado, la comparativística, es decir, una descripción comparada y comparativa del sistema lingüístico español y el sistema lingüístico ruso; y la descriptivística, a menudo basada en una tendencia a la ideología exaltadora de algunos niveles lingüísticos del español, en particular, de su "forma de sonar". Así, pues, la opinión académica del siglo XX sobre el sistema fonético-fonológico del español se sustenta en la ideología de su contraste fonético frente a otras lenguas europeas, por un lado, y su cercanía fonológica con la lengua rusa, por el otro. Ambas perspectivas van a menudo entrelazadas, dando lugar a una base ideológica comparativa continua.

Dentro de estas perspectivas ideológicas que, como acabamos de mencionar, no siempre son fáciles de separar la una de la otra, destacan por las reminiscencias en cuanto a la perceptividad del nivel fonético-fonológico del español, algunas obras de referencia del siglo XX. A estas pertenecen dos gramáticas clave en la enseñanza del español en la Unión Soviética: la Gramática comparada-contrastiva de las lenguas románicas (Сравнительно-сопоставительная грамматика романских языков), de Katagoschina y Volf (1968) (en adelante, Gramática comparada-contrastiva), y la Fonética práctica del español (Español: Практическая фонетика), de Barshak (1989).

En la primera de ellas, la Gramática comparada-contrastiva de Katagoschina y Volf, que contrasta el español con otra lengua de la familia ibérica, el portugués, encontramos una idea perceptiva subyacente sobre la forma de sonar de la lengua española. Frente a la lengua portuguesa, fonéticamente más inestable, el sonido español se define como seguro y constante: 
13. "Según la comparación [con el portugués], las vocales españolas (...) son constantes en su timbre" (1968: 9) 18 .

En los mismos autores, tiene lugar una apreciación sobre la espectacularidad vocálica - traducción literal del término usado - del español frente al portugués, debido a las particularidades articulatorias de las vocales españolas -su capacidad para convertirse en relajadas-y, por tanto, a su superior riqueza en la formación de grupos vocálicos (1968: 42). En lo relativo a las consonantes, la Gramática comparada-contrastiva refiere la gran flexibilidad combinatoria del elemento consonántico del español, que convierte esta lengua en fonéticamente conciliadora (1968: 76), es decir, capaz de sonar bien con cualquier unión consonántica que se pueda crear en ella.

También en la Fonética práctica del español de Barshak (1989) encontramos apreciaciones de base perceptiva que califican las emisiones vocálicas españolas en términos de sonido dinámico y puro, que conlleva a una impresión sonora particularmente coherente, rítmica y melódica:

14. "La articulación española destaca por ser enérgica (...), lo que dota sus vocales de una particular pureza” (Barshak, 1989: 16-17) ${ }^{19}$.

La tendencia a incluir valoraciones subjetivas sobre la fonética española frente a otros niveles lingüísticos sigue siendo una práctica habitual en obras metalingüísticas sobre el español, que con frecuencia recurren a destacar la cercanía de los sistemas fonéticos español y ruso como una vía de facilitación de la interferencia positiva durante su aprendizaje (Bondareva y Loginova, 2014: 84). Los trabajos más recientes sobre la fonética española — destacaremos el manual de Fonética española: curso primario (Фонетика испанского языка: вводный курс), de Makarova (2013); el estudio de las Funciones comunicativas y expresivas de entonemas (Коммуникативная и эмоциональная функции интонационных единиц), de Abakumova y Velichkova (2009); el ensayo Lengua española hoy y mañana (Испанский язык сегодня и завтра), de Romanova (2001); el estudio El sistema de oposiciones fonológicas como correlato del inventario fonético del consonantismo español (Система фонологических оппозиций как коррелят фонемного инвентаря испанского консонатизма), de Murashkina (2008), y el trabajo Convergencia y divergencia en los sistemas fonético y léxico-gramatical de las lenguas románicas (Конвергенция и дивергенция фонетического и лексикограмматического строя языков романской группы), de Petrunin (2013) - dan cuenta de esta aún persistente tendencia a ofrecer una valoración axiológica de la forma de sonar del español gracias a sus componentes segmentales y suprasegmentales. En el contexto de ideas que hablan de la relevancia semántica del patrón melódico (Makarova, 2016: 196) y del valor sintáctico y estilístico de la suprasegmentación española (Abakumova y Velichkova, 2009: 72), aparecen perspectivas que definen la fonética española como única por su forma de componerse, sonar y ser reconocida (Ro-

18. "Сравнение показывает, что в испанском языку все гласные ... не изменя[ют] своего основного тембра."

19. “Артикуляция звуков испанского языка отличается энергичностью (...), результатом которой является чистота гласных." 
manova, 2001). Este carácter único convive con otras características perceptivas, por ejemplo, con la definición del español como una lengua de sonido melódico y cantado:

15. "El carácter melódico y cantado del español se debe a sus cinco vocales, que representan alrededor del 50\% de su material sonoro" (Makarova, 2013: 7) ${ }^{20}$.

Frente a las vocales, también las consonantes desempeñan un papel esencial en que el español se perciba con una variabilidad sonora ininterrumpida debido a su repertorio alofónico consonántico heterogéneo (Murashkina, 2008 160, 164).

Desde la perspectiva prosódica, el español destaca por su patrón melódico más rico y más susceptible a la modulación que en otras lenguas debido a un número superior de entonemas, por lo que lo caracteriza una expresividad emocional mayor (Abakumova y Velichkova, 2009).

Sin duda alguna, la perspectiva académica más subjetiva en torno a la fonética española tiene sus raíces en Petrunin (2013), quien llega a afirmar que:

16. "Como otras lenguas románicas, el español cuenta con el sonido más encantador y maravilloso si se le compara con lenguas de otros grupos lingüísticos” (Petrunin, 2013: 66)²1.

\section{Conclusión}

La idea fundamental que se ha querido defender en este trabajo sostiene que la perspectiva gramatical actual sobre la fonética española desde el ámbito lingüístico ruso, como un contínuum que se extiende además a ámbitos privados y lejanos a la academia, se sustenta en puntos de anclaje individuales que crearon, en el siglo XIX, una perspectiva artística y perceptiva sobre la forma de sonar del español. Dicho de otra forma, podemos encontrar el origen de la teoría gramatical subjetiva rusa sobre la fonética española en unas fuentes lejanas a la lingüística y cercanas a los ámbitos de la música, hecho que, fuera de dudas, ha venido condicionando de forma sustancial la forma de explicar los principios fonéticos del español en las gramáticas hechas para rusohablantes.

En un estudio reciente apunta Astajova (2011: 60) que, para la mentalidad rusa, España se postula como una metáfora artística y emocional. En este sentido, la metáfora española que engloba alegría, fiesta, arte y, sobre todo, emociones, ha estado perviviendo desde hace más de un siglo y medio en el pensamiento sobre cómo suena la lengua española. El sonido de una lengua es lo primero a lo que se enfrenta una persona ajena a ella; por ello se lo responsabiliza de la formación de todas las posteriores actitudes que surgen en torno a la misma. El primer contacto consciente con la lengua

20. "Одной из наиболее характерных черт звукового строя испанского языка является высокая частотность употребления гласных, которые составляют около 50\% звукового материала. Мелодичность и напевность испанского языка в большой степени обязаны своим гласным."

21. "Романские языки обладают всеобщей и универсальной лексикой и самым очаровательным и чудесным звучанием среди прочих языковых групп." 
española fue de la mano de músicos e intelectuales decimonónicos, personas ajenas a la lingüística, y su percepción de la fonética española pasó por el filtro de la perceptividad musical. De allí que, desde entonces, los términos que definen la fonética española, incluso en el ámbito académico, reflejen su carácter melódico, expresivo, emotivo, ininterrumpido y alegre (definiciones ya casi terminológicas en el espacio ruso).

En este sentido, parece indudable que la formación de las ideologías lingüísticas sobre el español peninsular, en particular, sobre su sistema fonético-fonológico, ha estado siempre vinculada a la perspectiva comparativa y comparada del pensamiento gramatical dentro de un eje que, curiosamente, no nace en la propia lingüística sino en otras ramas humanísticas, como la música, la traducción literaria o la creación poética. Cabe, por tanto, plantearse que toda la actual tradición gramatical descriptiva del español desde el espacio rusohablante sigue la tónica ideológica de los inicios de la hispanística rusa: una perspectiva siempre comparativista, de base cognitivo-perceptiva más que puramente lingüística que nos lleva a prismas literario-musicales.

Curiosamente, como guinda del pastel, cabe mencionar que las ideas perceptivas decimonónicas de Glinka, Botkin y otros intelectuales dejan huella en la aprehensión actual de los rusos llanos, personas de a pie, sin vinculación alguna con el ámbito académico. Un rastreo rápido por diferentes foros dedicados a la enseñanza y el aprendizaje del español como lengua extranjera dejan una buena muestra de la pervivencia del mito español en la forma de pensar sobre la fonética española22.

17. "La lengua española suena muy melódica y espectacular".

18. "Un amigo filólogo me aconseja aprender español, y la idea me encanta puesto que esta lengua suena preciosa".

19. "La lengua española es increíblemente hermosa y sonante. No deja de hechizar con su temperamento, expresividad y energía”.

20. "El español es una lengua incomparablemente bonita. Atrae por su entonación, su dinamismo, su individualidad marcada. Es único, irrepetible”.

Como resultado, predomina la idea que vincula la hermosura del sonido del español con una aparente facilidad de su aprendizaje, algo bastante lejano a la realidad:

21. "La lengua española es la más fácil de entre las lenguas más comunes (...). Además, es una lengua preciosa y muy emotiva”.

22. Los ejemplos 17-21 pueden consultarse en los siguientes enlaces: http://otvet.mail.ru; http://forum.study.ru 
En definitiva, parece innegable que en la tradición rusa de pensar sobre la fonética española está anclada en la percepción musical. De allí que aún son muy frecuentes las obras académicas (y no tan académicas) que se dejan tentar por el ferviente deseo de incluir en una descripción o comparación puramente metalingüística un detalle manifiestamente ideológico sobre cómo suena el español. Este detalle, que podríamos caracterizar como inmaduro, poco científico o incluso infantil, no lo es, sin embargo, para una sociedad donde lo español (y, particularmente, la lengua española) siempre ha ido de la mano de la expresividad. 


\section{Bibliografía}

\section{Fuentes primarias}

Abakumova, O. у L. Velichkova (2009), “Коммуникативная и эмоциональная функции интонационных единиц" [Funciones comunicativas у expresivas de unidades entonativas], Вестник ВГУ. Серия: Лингвистика и межкультурная коммуникация [Boletín de la Universidad Estatal de Voronezh. Serie: Lingüística y comunicación intercultural], nº 1, p. 70-74.

Alpatov, Vladimir (2005), История лингвистических учений [Historia de la lingüística], Москва, Языки славянской культуры [Moscú, Lenguas de la cultura eslava].

Asafiev, Boris (1978), М.И. Глинка [M. Glinka], Ленинград, Музыка [Leningrado, Música].

Astajova, E. (2011), "Испания как метафора (к перекрестному году России в Испании и Испании в России)" [España como metáfora (a propósito del año de Rusia en España y España en Rusia)], Вестник МГИМО [Boletín del Instituto Estatal de Relaciones Internacionales de Moscú], nº 6 , p. 60-65.

Berezin, Fedor Mikhălovich (1984), История лингвистических учений [Historia de la lingüística], Москва, Высшая школа [Moscú, Escuela Superior].

Bondareva, V. e I. Loginova (2014), “Звуковая интерференция носителей некоторых романских языков в области русского вокализма" [Interferencia sonora en los hablantes nativos de algunas lenguas románicas en el ámbito del vocalismo ruso], Вестник Российского университета дружбы народов. Серия: Русский и иностранные языки и методика их преподавания [Воletín de la Universidad de la Amistad de los Pueblos de Rusia. Serie: Lengua rusa y lenguas extranjeras, y métodos de su enseñanza], n³, p. 82-86.

Calero Vaquera, María Luisa (2010), "Ideología y discurso lingüístico: la Etnortografía como subdisciplina de la glotopolítica”, Boletín de Filología, n² 2, p. 31-48.

Comrie, Bernard (1981), The languages of the Soviet Union, Cambridge, Cambridge University Press.

Filippov, Konstantin (2013), “Лейбниц-Вольф-Готтшед-Ломоносов: Квопросу ограмматических теориях XVIII века" [Leibniz - Wolff - Gottsched - Lomonosov: a propósito sobre las teorías gramaticales del S. XVIII], en П. Е. Бухаркин, С. С. Волков, Е. М. Матвеев (ред.), Филологическое наследие М. В. Ломоносова [Р. Bujarkin, Solomon Vólkov, E. Matveev (eds.), El legado filológico de M. Lomonósov], Санкт-Петербург, Нестор-История [San Petersburgo, Nestor-Historia], p. 253-264.

Gómez Asencio, José J., Esteban T. Montoro del Arco y Pierre Swiggers (2014), "Principios, tareas, métodos e instrumentos en historiografía lingüística”, en María Luisa Calero Alfonso Zamorano, Francisco Javier Perea, María del Carmen García Manga, María Martínez-Atienza, (eds.), Métodos y resultados actuales en Historiografía de la Lingüística, Münster, Nodus Publikationen, p. 266-301. 
Ivanova, Olga (2011), Sociolingüística urbana: estudio de usos y actitudes lingüísticas en la ciudad de Kiev, Salamanca, Ediciones Universidad de Salamanca.

Kaminskaia, Larisa (2015), “Словарь С. Палласа 'Linguarum totius orbis vocabularia comparative augustissimae cura collecta’ (1787, 1789 гг.) как источник фонетического исследования” [El diccionario de S. Pallas Linguarum totius orbis vocabularia comparative augistissimae cura collecta $(1787,1789)$ como fuente para el estudio fonético], Verbum, n 4, p. 70-78.

Klubkova, Tatiana (2016), "The First Russian Linguistic Questionnaire", Bulletin of the KIH of the RAS, n²3, vol. 1, p. 181-188.

Kogan, G. (1989): "Материалы по библиографии русских переводов Кальдерона” [Materiales para la bibliografía de las traducciones de Calderón al ruso], en Н.И. Балашов и Д.Г. Макогоненко, Педро Кальдерон де ла Барка. Драмы [N. Balashov у D. Makogonenko, Pedro Calderón de la Barca. Dramas], Москва, Наука [Moscú, Ciencia], p. 713-731.

Laborda, Xavier (2002), "Historiografía lingüística: veinte principios del programa de la investigación hermenéutica", Revista de Investigación Lingüística, n 1, vol. V, p. 179-207.

Lebedev, Evgeny (2010), Ломоносов [Lomonosov], Москва, ОГИ [Moscú, OGI].

Makarova, Tatiana (2013): Fonética española: curso primario. San Petersburgo: Caro.

Makarova, Elena (2016), “Фразовое ударение в испанском языке и особенности его реализации” [Grupos de intensidad en español y las peculiaridades de su colocación], Вестник КГУ им. Н.А. Некрасова [Boletín de la Universidad Estatal de Kostromá], n³, p. 195-197.

Murashkina, Olga Viktorovna (2008), "Система фонологических оппозиций как коррелят фонемного инвентаря испанского консонатизма” [El sistema de oposiciones fonológicas como correlato del inventario fonético del consonantismo español], Вестник ВГУ. Серия: Лингвистика и межкультурная коммуникация [Boletín de la Universidad Estatal de Voronezh], n³, p. 158-164.

Narodetskaya, А. (2010), "Испанские мотивы в камерно-вокальном творчестве Н.К. Метнера" [Motivos españoles en la creación de cámara y vocálica de N. Metner] Вестник Башкирского университета [Boletín de la Universidad de Bashkiria], nº 15, vol. 1, p. 75-78.

Petrunin, Mijail (2013), "Конвергенция и дивергенция фонетического и лексико-грамматического строя языков романской группы” [Convergencia y divergencia en los sistemas fonético y léxico-gramatical de las lenguas románicas], Гуманитарные науки. Педагогика и психология [Humanidades. Pedagogía y psicología], nº 6, vol. 122, p. 66-70.

Romanova, G. (2001), Испанский язык сегодня и завтра [Lengua española hoy у mañana], disponible en http://text.tr200.biz/referat_inostrannyj_jazyk.

Shuranov V. e I. Mijaliova (2016), “'Ночной зефир’ А.С. Пушкина: поэтический образ в романсах русских композиторов" ['Nochnoi zefir' de A. Pushkin: la imagen poética en los romances de los compositores rusos], Проблемы музакальной науки [Problemas de musicología], nº 2, p. 108115. 
Swiggers, Pierre (2004), "Modelos, métodos y problemas en la historiografía de la lingüística", en Cristóbal José Corrales Zumbado, Josefa Dorta Luis, Antonia Nelsi Torres González, Dolores Corbella Díaz, Francisca del Mar Plaza Picón (eds.), Nuevas aportaciones a la historiografía lingüística, vol. 1, Madrid, Arco/Libros, p. 113-146.

Swiggers, Pierre (2009), La historiografía de la lingüística: apuntes y reflexiones. Revista argentina de historiografía lingüística, nº, vol. 1, p. 67-76.

Tishko, Sergey Vitalyevich y Galina Vitalyevna Kukol (2011), "Spain as seen by Glinka: travel and stopover", Art of Music. Theory and history, n 1-2, p. 240-271.

Zhivov, Victor Markovich (1996), Язык и культура в России XVIII века [Lengua у cultura en Rusia del siglo XVIII], Москва, Языки русской школы [Moscú, Las lenguas de la escuela rusa].

\section{Fuentes consultadas}

Bacmeister, Ludwig (1773), Idea et desideria de colligendis linguarum speciminibus, Санкт-Петербург, При Академии [San Petersburgo, Academia].

Barshak, M. (1989), Español: Практическая фонетика [Fonética práctica del español], Москва, Высшая школа [Moscú, Escuela superior].

Botkin, Vasili Petróvich (1857) Письма об Испании [Cartas sobre España], Санкт-Петербург, тип. Эдуарда Праца [San Petersubrgo, editoria de Eduardo Pratz].

Glinka, Mijail (1973-1977), Полное собрание сочинений. Литературные произведения и переписка [Obras completas. Obras literarias y cartas], Москва, Музыка [Moscú, Música].

Glinka, Mijail (2012), Письма и документы [Cartas y documentos], Москва, Директ медиа [Moscú, Direct Media].

Katagoschina, N. y E. Volf (1968), Сравнительно-сопоставительная грамматика романских языков [Gramática comparada-contrastiva de las lenguas románicas], Москва, Академия Наук СССР [Moscú, Academia de las Ciencias de la URSS].

Lomonosov, Mijail (1755), Полное собрание сочинений [Obras completas], Москва, Издательство Академии наук CCCP [Moscú, Academia de las Ciencias de la URSS].

Pallas, Simeón (1787-1789), Linguarum totius orbis vocabularia comparative augustissimae cura collecta, Санкт-Петербург, Johannes Carolus Schoor [San Petersburgo, Johannes Carolus Schoor].

Rimski-Korsakov, Nikolai (1866), Летопись моей музыкальной жизни [Crónicas de mi vida musical], Москва, Государственное музыкальное издательство [Moscú, Editorial musical estatal]. 